\title{
Role of Medial Prefrontal Cortex Serotonin 2A Receptors in the Control of Retrieval of Recognition Memory in Rats
}

\author{
Pedro Bekinschtein, ${ }^{1}$ Maria Constanza Renner, ${ }^{1}$ Maria Carolina Gonzalez, ${ }^{1}$ and Noelia Weisstaub ${ }^{1,2}$ \\ ${ }^{1}$ Instituto de Biología Celular y Neurociencias, Facultad de Medicina, UBA-CONICET, Paraguay 2155 3er piso, Buenos Aires (C1121ABG), Argentina and \\ ${ }^{2}$ Grupo de Neurociencia de Sistemas, Departamento de Fisiología, Facultad de Medicina, UBA, Paraguay 2155 7mo piso, Buenos Aires (C1121ABG), \\ Argentina
}

Often, retrieval cues are not uniquely related to one specific memory, which could lead to memory interference. Controlling interference is particularly important during episodic memory retrieval or when remembering specific events in a spatiotemporal context. Despite a clear involvement of prefrontal cortex (PFC) in episodic memory in human studies, information regarding the mechanisms and neurotransmitter systems in PFC involved in memory is scarce. Although the serotoninergic system has been linked to PFC functionality and modulation, its role in memory processing is poorly understood. We hypothesized that the serotoninergic system in PFC, in particular the 5-HT2A receptor (5-HT2AR) could have a role in the control of memory retrieval. In this work we used different versions of the object recognition task in rats to study the role of the serotoninergic modulation in the medial PFC (mPFC) in memory retrieval. We found that blockade of 5-HT2AR in mPFC affects retrieval of an object in context memory in a spontaneous novelty preference task, while sparing single-item recognition memory. We also determined that 5-HT2ARs in mPFC are required for hippocampal-mPFC interaction during retrieval of this type of memory, suggesting that the $\mathrm{MPFC}$ controls the expression of memory traces stored in the hippocampus biasing retrieval to the most relevant one.

\section{Introduction}

Remembering is more than the activation of a single memory trace. So how are we able to retrieve specific memories? As retrieval cues are often not uniquely related to a particular memory, there should be a mechanism to allow selective memory retrieval by focusing on relevant (and ignoring irrelevant) information. This is important during episodic memory (Squire, 2004). Most of what we know about the mechanisms that control interference comes from human studies (Ferbinteanu et al., 2006). Although the anatomical basis of episodic memory has been extensively studied, the neurobiological mechanisms are largely unknown (Wheeler et al., 1995; Nyberg et al., 2000; Burgess et al., 2001; Hayes et al., 2004). Thus, the development in animals of behavioral tasks that model episodic memory is essential. Some aspects of episodic memory have been modeled using object recognition (Eacott and Norman, 2004; Ergorul and Eichenbaum, 2004; Warburton and Brown, 2010; Easton et al., 2012). Animal studies

Received May 16, 2013; revised July 29, 2013; accepted Aug. 21, 2013.

Author contributions: P.B. and N.W. designed research; P.B., M.C.R., M.G., and N.W. performed research; P.B., M.C.R., and N.W. analyzed data; P.B. and N.W. wrote the paper.

This work was supported by research grants from the National Agency of Scientific and Technological Promotion of Argentina to N.W. (PICT 2008-00072 and PICT 2008-1065). We thank Dr Jorge H. Medina, Dr. Nicolás Merener, and Dr. Lionel Müller Igaz for helpful discussion of this manuscript and also Ezequiel Kozack for technical help.

The authors declare no competing financial interests.

Correspondence should be addressed to either Noelia Weisstaub or Pedro Bekinschtein, Grupo de Neurociencia de Sistemas, Departamento de Fisología, Facultad de Medicina, UBA, Paraguay $21557 \mathrm{mo}$ piso, Buenos Aires (C1121ABG), Argentina. E-mail: nweisstaub@fmed.uba.ar or pbekinschtein@fmed.uba.ar.

M.C. Renner's present address: Netherlands Institute for Neuroscience, Royal Netherlands Academy of Arts and Sciences, Meibergdreef 47, 1105BA Amsterdam, The Netherlands.

DOI:10.1523/JNEUROSCI.2087-13.2013

Copyright $\odot 2013$ the authors $\quad 0270-6474 / 13 / 3315716-10 \$ 15.00 / 0$ using tasks that employ a subset of episodic memory features have provided relevant mechanistic information (Farovik et al., 2008; Langston and Wood, 2010; Warburton and Brown, 2010; Navawongse and Eichenbaum, 2013). Spontaneous recognition memory tasks are short, simple, and free from stress (for review, see Winters et al., 2010). They require judgment regarding the previous occurrence of stimuli, which can be made on the basis of the relative familiarity, recency, or by integrating information concerning objects and location (Brown et al., 1987; Gaffan, 1992; Fahy et al., 1993; Li et al., 1993; Meunier et al., 1993; Ennaceur et al., 1996; Murray and Bussey, 1999; Bussey et al., 2000; Brown and Aggleton, 2001; Kesner and Ragozzino, 2003; Hannesson et al., 2004a, b; Browning et al., 2005; Barker et al., 2007; Barker and Warburton, 2011; Navawongse and Eichenbaum, 2013). Rodents naturally tend to approach and explore novel objects, which are assumed to have no natural significance to the animal and which have never been paired with a reinforcing stimulus. They also show an innate preference for novel over familiar objects. They readily approach objects and investigate them physically by touching and sniffing them, rearing upon and trying to manipulate them with their forepaws (Aggleton et al., 1989; Ennaceur and Aggleton, 1994). This behavior can be easily quantified and used to study simple recognition memory as well as more complex spatial-, temporal-, and episodic-like memory in rodents.

The prefrontal cortex (PFC) is a key area involved in topdown cognitive control, like response selection, inhibitory control (Miller, 2000; Fuster, 2001; Miller and Cohen, 2001; Miller and Wang, 2006), suppression of unwanted memories, recall of remote memories (Anderson et al., 2004; Frankland and Bontempi, 2005), and episodic recollection (see above). The PFC 
receives a broad range of sensory and limbic inputs that can activate contextually appropriate representations of goals or task rules (Miller and Cohen, 2001). It directly projects to the perirhinal cortex and to the hippocampus via the parahippocampus, the subiculum, and the presubiculum (Goldman-Rakic et al., 1984; Price, 1999; Petrovich et al., 2001). Reciprocal connections project back to the PFC.

Although the serotoninergic system has been linked to PFC function (Martín-Ruiz et al., 2001; Puig et al., 2004, 2005), its role in memory processing is poorly understood. The 5-HT2A receptor (5-HT2AR) is one of the main postsynaptic serotoninergic receptor types and it is highly expressed in the PFC. (Boulougouris et al., 2007). The expression pattern of 5-HT2AR and its role in PFC cellular physiology suggest that it is important for the modulation of PFC-dependent functions, including attentional control, cognitive flexibility, and impulsivity (Winstanley et al., 2003; Carli et al., 2006; Baker et al., 2011). However, the role of serotonin and, particularly, 5-HT2AR in memory processing remain largely an important question. A handful of studies suggest a role for 5-HT2AR in episodic memories in humans (de Quervain et al., 2003; Wagner et al., 2008). A few animals studies have addressed a potential role of 5-HT2AR during memory consolidation (Meneses et al., 1997; Meneses, 2007; Wagner et al., 2008). However, we know very little regarding the role of the serotoninergic system and particularly, 5-HT2AR in episodic memory retrieval. Moreover, since 5-HT2AR is highly expressed in PFC, we hypothesized that 5-HT2AR signaling in PFC could have a role in the control of episodic memory expression.

In this study we chose different versions of the spontaneous novel object recognition task that model some features of episodic memory to analyze the role of the serotoninergic modulation via the 5-HT2AR in the medial PFC (mPFC) during memory retrieval. We hypothesize that top-down control from $\mathrm{mPFC}$ through 5-HT2AR signaling would be required for accurate memory retrieval only in the cases in which the task cannot be solved using an item-only strategy and a combination of multiple elements is required.

\section{Materials and Methods}

\section{Subjects}

162 male adult Wistar rats (weight $180-250 \mathrm{~g}$ ) were housed five per cage and kept with water and food ad libitum under a $12 \mathrm{~h} \mathrm{light/dark} \mathrm{cycle}$ (lights on at 7:00 A.M.) at a constant temperature of $23^{\circ} \mathrm{C}$. Experiments took place during the light phase of the cycle (between 10:00 A.M. and 5:00 P.M.) in a quiet room with dim light. The experimental protocol for this study was approved by the National Animal Care and Use Committee of the University of Buenos Aires.

\section{Surgery and drug infusions into the $m P F C$}

Rats were deeply anesthetized with ketamine $(60 \mathrm{mg} / \mathrm{kg})$ and xylazine $(8$ $\mathrm{mg} / \mathrm{kg}$ ) and placed in a stereotaxic frame. The skull was exposed and adjusted to place bregma and lambda on the same horizontal plane. After small burr holes were drilled, a set of $22 \mathrm{~g}$ guide cannulae were implanted bilaterally into the mPFC [anterior-posterior (AP) $+3.20 \mathrm{~mm} /$ lateral (L) $\pm 0.75 \mathrm{~mm} /$ dorsoventral (DV) $-3.50 \mathrm{~mm}$ ] (see Fig. 1B). Cannulae were fixed to the skull with dental acrylic. A dummy cannula was inserted into each guide cannula to prevent clogging. At the end of surgery, animals were injected with a single dose of meloxicam $(0.2 \mathrm{mg} / \mathrm{kg})$ as analgesic. Behavioral procedures commenced 5-7 d after surgery.

On the experimental day, the dummy cannulae were removed and a $30 \mathrm{~g}$ injection cannula extending $1 \mathrm{~mm}$ below the guide cannula was inserted. The injection cannula was connected to a $10 \mu \mathrm{l}$ Hamilton syringe. Cannulated rats received bilateral $0.8-1 \mu \mathrm{l}$ infusions of the appropriate drug or vehicle into the MPFC 15 min before testing. MDL 11,939 (Tocris Bioscience), ergotamine (Sigma), and SB 242084 (Tocris Biosci- ence) were dissolved in pure dimethylsulfoxide (DMSO) and diluted in saline to final concentration of $300 \mathrm{ng} / \mu \mathrm{l}(<10 \% \mathrm{DMSO})$ and $8-\mathrm{OH}$ DPAT (Sigma) was dissolved in saline.

\section{Surgery and drug infusions for the disconnection experiment}

For the disconnection experiment (see Fig. 6), rats were anesthetized and put in the stereotaxic frame as described before. Two pairs of $22 \mathrm{~g}$ cannulae were used. One pair was bilaterally implanted in the MPFC and the other pair was implanted bilaterally in the hippocampus ( $\mathrm{AP}-3.90$ $\mathrm{mm} / \mathrm{LL} \pm 3.00 \mathrm{~mm} / \mathrm{DV}-3.00 \mathrm{~mm})$. On the experimental day, rats were infused with MDL 11,939 (300 $\mathrm{ng} / \mu \mathrm{l})$ in the $\mathrm{mPFC}$ and muscimol $(0.1$ $\mu \mathrm{g} / \mu \mathrm{l}$; Sigma) in the hippocampus.

For this experiment rats were divided into four groups. The first group received a bilateral injection of MDL 11,939 in the MPFC and vehicle in the hippocampus. The second group received a bilateral injection of vehicle in the $\mathrm{mPFC}$ and muscimol in the hippocampus. The third group received a contralateral injection of MDL 11,939 in the MPFC and muscimol in the hippocampus. The fourth group received an ipsilateral injection of MDL 11,939 in the MPFC and muscimol in the hippocampus.

\section{Behavioral experiments}

Statistical analysis. Behavioral data were analyzed using unpaired Student's $t$ test when two groups were compared and one-way ANOVA followed by Newman-Keuls multiple comparisons or Tukey's multiple comparisons as indicated in the figure legends.

Simple object recognition and temporal order recognition tasks. Simple object recognition (SOR) and temporal order recognition (temporal memory object recognition, TMOR) tasks were conducted in a Y-shaped apparatus, as described previously (Winters et al., 2004; Forwood et al., 2007). Briefly, the Y-apparatus had high, homogenous white walls constructed from Plexiglas to prevent the rat from looking out into the room, thereby maximizing attention to the stimuli. All walls were $40 \mathrm{~cm}$ high, and each arm was $27 \mathrm{~cm}$ in length and $10 \mathrm{~cm}$ wide. The start arm contained a guillotine door $18 \mathrm{~cm}$ from the rear of the arm. This provided a start box area within which the rat could be confined at the start of a given trial. Duplicate copies of objects made from plastic, ceramic, glass, and aluminum were used. The height of the objects ranged from 8 to $24 \mathrm{~cm}$ and they varied with respect to their visual and tactile qualities. All objects were affixed to the floor of the apparatus with an odorless reusable adhesive to prevent them for being displaced during each session. As far as we could determine the objects had no natural relevance for the rats and they have never been associated with a reinforcer. The objects, floor, and walls were cleaned with ethanol $50 \%$ between experiments.

All rats were habituated to the context the day before the beginning of the task. They were allowed to explore the empty Y-shaped apparatus for $10 \mathrm{~min}$. For these habituation sessions, the rat was placed in the start box, and the guillotine door was opened to allow the rat to explore the main area of the apparatus. The guillotine door was lowered when the rat exited the start box to prevent re-entry into this area of the apparatus. Testing began $24 \mathrm{~h}$ later in each experiment.

SOR. To address whether simple object discrimination was affected by 5-HT2AR blockade, we used the SOR task. Each trial consisted of two phases (see Fig. $3 A$ ). In the sample phase, two identical objects (A1 and A2) were placed in the Y-shaped apparatus, one at the end of each exploration arm. The rat was placed in the start box with the guillotine door lowered. The guillotine door was then raised to allow the rat into the exploration area of the maze and was allowed to explore the objects for 5 min. The time spent exploring the two objects was scored by an experimenter viewing the rat. Exploration of an object was defined as directing the nose to the object at a distance of $<2 \mathrm{~cm}$ and/or touching it with the nose. Turning around or sitting on the object was not considered exploratory behavior.

At the end of the sample phase, the rat was removed from the Y-shaped apparatus and returned to its home cage for the duration of the retention period. After the delay, the rat was placed back in the start box of the Y-shaped apparatus and released into the exploration area for the choice phase. The Y-shaped apparatus now contained an identical copy of the sample (familiar) object (A3) in one arm and a new object (B) in the other. The exploration arms in which the choice objects were placed were 
counterbalanced between rats. The rat was allowed to explore the objects for $3 \mathrm{~min}$, at the end of which it was removed and returned to its home cage. We calculated a discrimination ratio defined as the proportion of total exploration time spent exploring the novel object (i.e., the difference in time spent exploring the novel and familiar objects divided by the total time spent exploring the objects).

TMOR. To address if recency memory retrieval is affected by 5-HT2AR blockade, we conducted a TMOR task. This task comprised two sample phases and one test trial (see Fig. 2A). It was conducted in the same apparatus as the SOR task. In each sample phase, the subjects were allowed to explore two copies of an identical object for $5 \mathrm{~min}$. Different objects were used for sample phases 1 and 2 , with a $1 \mathrm{~h}$ delay between the sample phases. The test trial ( 3 min duration) was given $3 \mathrm{~h}$ after sample phase 2. During the test trial, a copy of the objects from sample phase 1 and a copy of the objects from sample phase 2 were used. The positions of the objects in the test and the objects used in sample phase 1 and sample phase 2 were counterbalanced between the animals.

Simultaneous oddity discrimination task. The simultaneous oddity discrimination (SOD) task was conducted to evaluate if infusion of the 5-HT2AR antagonist affected attention and perception. The oddity apparatus incorporated the same considerations used to design the Y-apparatus. The exploration area was triangular in shape (Fig. 3E). The oddity apparatus had high, homogenous white walls constructed from Perspex to prevent the rat from looking out into the room. All walls were $30 \mathrm{~cm}$ high and the three sides of the triangular area were $75 \mathrm{~cm}$ long. The back wall was $84 \mathrm{~cm}$ wide and $59 \mathrm{~cm}$ tall, and the objects were placed 2.50 $\mathrm{cm}$ apart along the back wall. All rats were habituated to the empty apparatus for $10 \mathrm{~min}$ in which they were allowed to freely explore it. For the habituation session, the rat was placed in the triangular apparatus, facing the corner of the triangle away from the stimuli. Testing began $24 \mathrm{~h}$ after the habituation session. All object sets used in a given trial were placed in the apparatus before the rat was placed in the apparatus. The rat was placed in the corner of the triangular apparatus (away from the stimuli), and the trial did not begin until the rat turned around and entered the main exploration area. The time spent exploring the three objects during a testing phase was scored by an experimenter viewing the rat. Exploration of an object was defined as directing the nose to the object at a distance of $<2 \mathrm{~cm}$ and/or touching it with the nose.

Object in context recognition task. To evaluate if retrieval of an object in a particular context was affected by infusion of MDL 11,939 in the MPFC, we used the object in context (OIC) recognition task. For OIC recognition, we used two arenas with different physical features. The first apparatus (context 1) was a $50 \mathrm{~cm}$ wide $\times 50 \mathrm{~cm}$ length $\times 39 \mathrm{~cm}$ height arena with black plywood walls and floor, divided into nine squares by white lines. The second apparatus (context 2) was a $60 \mathrm{~cm}$ wide $\times 40 \mathrm{~cm}$ length $\times 50 \mathrm{~cm}$ height acrylic box. The floor was white as well as two of its walls, which had different visual clues. The frontal wall was transparent and the back wall was hatched. All rats were habituated in a daily session in which they were allowed to explore each apparatus for $10 \mathrm{~min}$. The test began $24 \mathrm{~h}$ later, using objects that had the same characteristics described in the previous experiments.

On sample phase 1 , rats were placed in context 1 facing the wall opposite the objects and were allowed to explore two identical objects (A1 and A2) for $5 \mathrm{~min}$ (Fig. 1A). In sample phase 2, conducted $1 \mathrm{~h}$ later, rats were placed in context 2 together with two identical new objects (B1 and B2) and were allowed to explore the objects for $5 \mathrm{~min}$. Memory was tested $3 \mathrm{~h}$ later. On the memory test, rats were reintroduced to context 1 or 2 (pseudorandomly assigned) and were allowed to explore ad libitum for 3 min one copy of object A and one copy of object B. The time spent exploring the two objects was scored during the testing phase.

OIC recognition task with three objects. The same contexts were used and animals were habituated as previously described. Animals were exposed to three identical objects (A1, A2, and A3) for 5 min and reexposed to the same context and objects 15 min later (see Fig. $4 C$ ). One hour later the animals were placed in context 2 together with three identical new objects (B1, B2, and B3) and were allowed to explore them for 5 $\mathrm{min}$. On the memory test rats were reintroduced to the first context and allowed to explore ad libitum for 3 min one copy of A, one copy of B, and

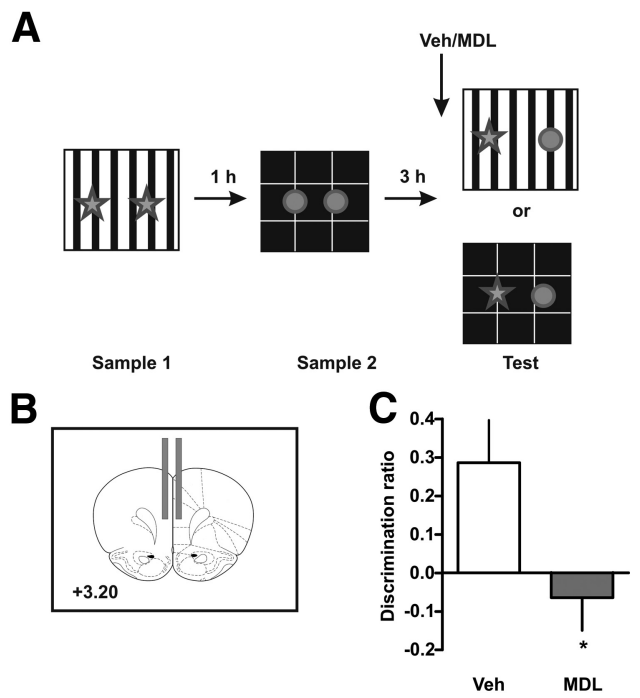

Figure 1. Blockade of 5-HT2AR in mPFC impairs OIC recognition memory retrieval. $\boldsymbol{A}$, Training and testing scheme. Animals were exposed to a context containing two identical copies of an object for $5 \mathrm{~min}$. An hour later they were exposed to a different context containing two identical copies of a different object. Three hours later they were re-exposed to context A or B containing one copy of each of the objects. $B$, Schematic representation of the sites of injection. Fifteen minutes before the test session rats were infused with $300 \mathrm{ng} / \mu$ IMDL 11,939 or vehicle (Veh) into the mPFC. C, Discrimination index was calculated as the time spent exploring the incongruent object minus the time spent exploring the congruent object over the total exploration time during the test session; $n=8-9$ per group, ${ }^{*} p<0.05$, Student's $t$ test.

Table 1. Total exploration scores during sample phase for the TMOR, OIC, NOR, object-location, and OIC with novelty tasks

\begin{tabular}{|c|c|c|c|c|c|c|c|}
\hline & $A$ & $A^{\prime}$ & $p$ & B & $B^{\prime}$ & $p$ & $N$ \\
\hline TMOR & $18.37 \pm 1.81$ & $19.05 \pm 1.9$ & 0.8 & $17.39 \pm 2.68$ & $16.58 \pm 2.48$ & 0.82 & 16 \\
\hline OIC & $15.32 \pm 1.43$ & $13.91 \pm 1.43$ & 0.49 & $13.67 \pm 1.23$ & $16.37 \pm 1.76$ & 0.22 & 18 \\
\hline SOR & $24.33 \pm 2.43$ & $25.84 \pm 2.43$ & 0.66 & & & & 15 \\
\hline Object location & $16.15 \pm 2.82$ & $14.23 \pm 2.4$ & 0.62 & & & & 8 \\
\hline OIC with novelty & $14.71 \pm 1.36$ & $13.50 \pm 1.42$ & 0.55 & $13.00 \pm 1.21$ & $15.84 \pm 1.67$ & 0.178 & 824 \\
\hline
\end{tabular}

Values are expressed in seconds as mean \pm SEM. $A, A^{\prime}$ and $B, B^{\prime}$ indicate each one of the identical objects used. There were no significant differences in time exploring each one of the objects, Student's $t$ test.

a new object (C). The order of the context exposure was pseudorandomly assigned.

\section{Results}

Blockade of mPFC 5-HT2AR affects the OIC recognition task The OIC recognition task is a three-trial procedure (Wilson et al., 2013). In this case, the rats are exposed, during the sample phase, to two different pairs of identical objects presented in different contexts (Fig. 1A). These presentations are separated by an hour. During the retention trial, performed $3 \mathrm{~h}$ after the last presentation, a new copy of each of the objects used before is presented in one of the contexts (pseudorandomly assigned). Thus, one of the objects is presented in an "incongruent" context, while the other is being presented in a "congruent" one. In this task, novelty comes from a novel combination of an object and a context, and exploration will be driven by retrieval of a particular "what" and "which context" conjunctive representation. The animals showed no differences in the exploration levels in each context during the training session (see Table 1), neither did they show differences in the exploratory level during the test session (see Table 2). However, blockade of the mPFC 5-HT2AR with the 5-HT2AR antagonist MDL 11,939 15 min before the retention trial produced a significant difference in the level of exploration of both objects compared with vehicle-treated rats. As it has been 
Table 2. Total exploration scores during test phase for the TMOR, OIC, NOR, SOD, object-location, and OIC with novelty tasks

\begin{tabular}{llllr}
\hline & Veh & MDL & $p$ & $N$ \\
\hline TMOR & $28.46 \pm 3.27$ & $30.84 \pm 4.77$ & 0.69 & 8 \\
OIC & $10.69 \pm 2,02$ & $12.48 \pm 1,13$ & 0.45 & 9 \\
SOR & $22.48 \pm 3,90$ & $21.21 \pm 2,08$ & 0.77 & 8 \\
SOD & $24.33 \pm 4.24$ & $17.20 \pm 2.66$ & 0.16 & 7 \\
Object location & $14.54 \pm 4.85$ & $16.39 \pm 2.11$ & 0.73 & 4 \\
OIC with novelty & $15.63 \pm 4.12$ & $15.11 \pm 1.78$ & 0.9 & 10 \\
\hline
\end{tabular}

Values are expressed in seconds as mean \pm SEM. MDL-injected rats showed no differences in total exploration scores compared with Veh-injected rats, Student's $t$ test.

shown before, vehicle-treated rats showed a preference for the incongruent object as reflected by their increased levels of exploration of this object compared with the congruent one (Fig. $1 C$; $\left.t_{(15)}=2.54, p=0.0223\right)$. In contrast, rats infused with MDL 11,939 showed no preference for any of the objects. There were no significant differences in the total levels of exploration across groups, suggesting that the blockade of 5-HT2AR affected the capability to discriminate in which context they had seen the objects and not their exploratory drive. This result strongly suggests that blockade of mPFC 5-HT2AR affects the capability of the animals to discriminate between two known objects that have been previously shown in different contexts.

\section{Blockade of mPFC 5-HT2AR disrupts the temporal order object recognition task}

The TMOR measures the ability of the animals to discriminate the relative recency with which they have seen two different objects. This task is a three-trial procedure, composed of two sample trials separated by $1 \mathrm{~h}$ and a retention trial $3 \mathrm{~h}$ later. It has been shown that rats display a preference for the "older" object during the retention trial and this has been taken as a measure of recency memory (Barker et al., 2007). Rats were trained in TMOR and their memory was tested. Total exploration times during testing showed no differences between groups (see Table 2). Injection of MDL 11,939 in the mPFC 15 min before the retention test affected the animals response in the TMOR compared with the animals injected with vehicle (Fig. $2 B ; t_{(12)}=2.85, p=0.0146$ ). The discrimination ratio shows that rats infused with MDL 11,939 explored both objects to the same extent showing no recency discrimination. There were no significant differences in level of exploration during the training phase (see Table 1).

\section{No effect of mPFC 5-HT2AR blockade in the SOR task or in the object-location task}

The amnesia observed in the TMOR and OIC tasks could be simply explained by a deficit in object recognition, that is, the rats are forgetting both objects, independently of whether they were explored more or less recently or in different contexts. To investigate whether mPFC 5-HT2AR is also necessary for an SOR in which no requirement is imposed for associating objects and context or order, we tested rats in an SOR task, which implies one sample trial and a retention trial $3 \mathrm{~h}$ later. Infusion of MDL 11,939 into the mPFC $15 \mathrm{~min}$ before the retention test did not affect the ability of the rats to discriminate between a familiar and a novel object as it is shown by the discrimination ratio (Fig. $3 B ; t_{(13)}=$ $1.207, p=0.2490$ ) neither did it affect the total exploration time (see Table 2). These results suggest that the activity of 5-HT2AR in the $\mathrm{mPFC}$ is not necessary for retention in the SOR task and thus the deficit in the TMOR and OIC tasks cannot be explained by an impairment in object discrimination per se. Another possibility is that blockade of mPFC 5-HT2AR impairs retrieval of

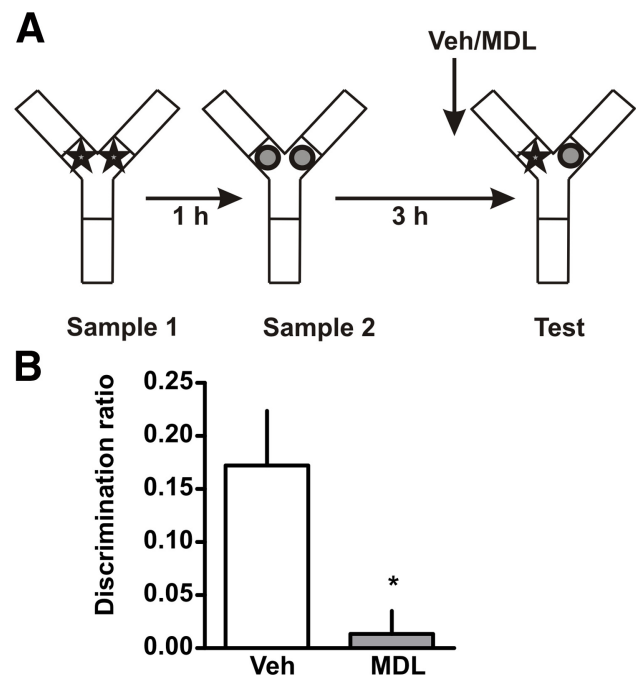

Figure 2. Blockade of 5-HT2AR in mPFC impairs recency discrimination during retrieval. $A$, Training and testing scheme. Animals were exposed to an arena containing two identical copies of an object and an hour later re-exposed to the same arena containing two identical copies of a different object. Three hours later rats were exposed to the same context containing one copy of each object. $B$, Fifteen minutes before the test session rats were infused with $300 \mathrm{ng} / \mu \mathrm{lMDL}$ 11,939 or vehicle (Veh) into the $\mathrm{mPFC}$. Discrimination index was calculated as the time spent exploring the older object minus the time spent exploring the recent object over the total exploration time during the test session; $n=7$ per group, ${ }^{*} p<0.05$, Student's $t$ test.

the context, a treatment that could cause the deficit in the OIC task. This can be ruled out since infusion of MDL 11,939 into the mPFC 15 min before the retention test did not affect performance in an object-location task (Fig. 3D). This task implies one sample phase and a retention trial phase (Fig. $3 C$ ). Novelty is determined by a change in the location of one of the objects, but not the object identity. If retrieval of the context had been affected, then rats should have explored both objects equally during the retention test (and show a lower discrimination ratio), but there were no differences between groups.

\section{Blockade of mPFC 5-HT2AR does not affect attention and perception}

The $\mathrm{mPFC}$ is highly involved in attention and perception processes as has been shown across different tasks (Robbins, 1996; Miller and Cohen, 2001). Since our results could be explained by differences in attention or perception we decided to directly test this hypothesis using the SOD task (Bartko et al., 2007). This task consists of a single trial in which animals are exposed simultaneously to three objects from which two of them are identical (Fig. $3 E)$. It has been shown that animals tend to divide their exploratory time between the two identical copies resulting in an apparent preference for the single object. We found that independently of the infusion of MDL 11,939 into the MPFC, both groups explore more the odd object (Fig. $3 F ; t_{(12)}=0.3181, p=0.7559$ ) with no significant differences in the total exploration time (see Table 2), suggesting that the differences observed in the OIC and TMOR tasks are not due to changes in attention or perception as a result of the infusion of the 5-HT2AR antagonist.

Performance is not affected by blockade of mPFC 5-HT2AR if a familiar object is replaced by a novel object after OIC training

The next set of experiments was focused in understanding the nature of the OIC task, as we wanted to assess the mechanisms involved in the what, where aspect of episodic memory. Blockade of mPFC 
5-HT2AR precluded the capacity of the rats to discriminate between congruent and incongruent objects in the OIC task. Thus, one hypothesis could be that the infusion of MDL 11,939 causes forgetting of both objects in this different setup (i.e., two contexts and two sets of familiar objects). To test this hypothesis we designed a similar experiment in which animals were trained in the same OIC task as described before but the incongruent object was swapped for a novel object during the testing phase (Fig. 4A). We found that both groups, independently of the infusion of MDL 11,939 or vehicle, spent more time exploring the novel object compared with the congruent one (Fig. $4 B$; $t_{(16)}$ $=0.6017, p=0.5558)$. Although this experiment suggests that animals infused with MDL 11,939 are able to recognize novelty, we modified the OIC task to assess the level of exploration of the congruent, incongruent, and novel object simultaneously. This design allowed us to evaluate if the blockade of mPFC 5-HT2AR produced a deficit in the retrieval of the previously known objects (both objects are seen as novel) or if the blockade allowed interference between the traces of the two known objects (both objects are seen as congruent or incongruent). In animals infused with vehicle, we found a significant difference in the level of exploration across the three objects (Fig. 4D; oneway ANOVA, $\left.F_{(3)}=72.77, p<0.0001\right)$. Post hoc analysis (Newman-Keuls multiple comparisons) showed that they significantly explored more the novel object than the other two $(p<0.05)$ and explored more the incongruent than the congruent one $(p<$ $0.05)$. However, the animals infused with MDL 11,939 showed a different pattern of exploration. An ANOVA analysis showed there were significant differences in the level of exploration $\left(F_{(3)}=12.20, p<0.0001\right)$. They significantly explored the novel object more than the other two (Fig. $4 D$, right; $p<0.05$ ) but showed no significant differences in the level of exploration between the congruent and the incongruent one $(p>0.05)$. Interestingly, the level of exploration of both objects is similar to the level of exploration of the incongruent one from the control group. Thus, SOR is unaffected by MDL 11,939, but the OIC component of the task is abolished by this treatment. This means that rats remember having seen the objects, but they do not remember in which context they have seen them.

\section{Blockade of mPFC 5-HT2AR but no mPFC 5-HT2CR affects the OIC task}

Although the 5-HT2AR is one of the main excitatory serotoninergic receptors in the cortex, there are other serotoninergic receptors expressed in cortical cells, like the 5-HT2CRs. 5-HT2CRs are closely related to the 5-HT2AR and MDL 11,939 has been shown to have some affinity for them (Pehek et al., 2006). For that reason, we wanted to evaluate the role of the 5-HT2CR in the OIC task. We found that the infusion of SB 242058, a potent and very specific 5-HT2CR antagonist (Kennett et al., 1997), did not affect
B

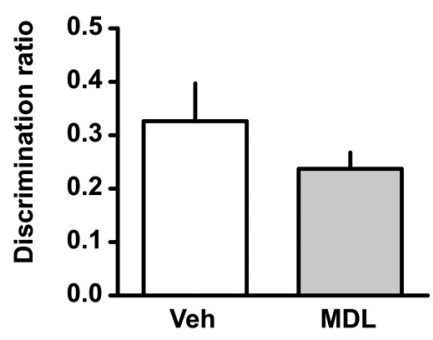

D

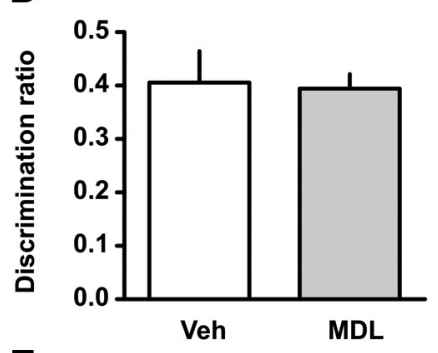

$\mathbf{F}$

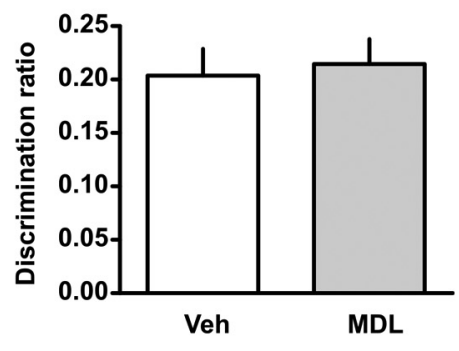

Figure 3. Spontaneous novel object recognition, objection location, and perception are not affected by the blockade of 5-HT2AR in mPFC. A, Training and testing scheme for the SOR. B, Animals were trained in SOR and $15 \mathrm{~min}$ before the test session were infused with $300 \mathrm{ng} / \mu \mathrm{l} \mathrm{MDL} 11,939$ or vehicle (Veh) into the mPFC. Discrimination index was calculated as the time spent Training and testing scheme for the object-location task. $\boldsymbol{D}$, Fifteen minutes before testing rats were infused with MDL 11,939 or exploring the object in the novel location minus the time $F$. Fifteen minutes before the experiment rats were infused with $300 \mathrm{ng} / \mu \mathrm{IMDL} 11,939$ or vehicle (Veh) into the mPFC. Discrimination index was calculated as time spent exploring the odd object minus half mean of the time exploring the repeated object divided by total exploratory time. $n=4-8$ per group, $p>0.2$, Student's $t$ test.

the response of the animals in the OIC task (Fig. $5 B$; one-way ANOVA followed by a post hoc analysis; $\left.F_{(4)}=6.685, p>0.005\right)$, strongly suggesting that the effect described before is due to the blockade of 5-HT2AR specifically.

\section{Activation of 5-HT1AR also affects the OIC task}

5-HT1ARs are the main serotoninergic receptors in the cortex and are coupled to inhibitory $G_{i}$ proteins. It has been shown that a high proportion of cortical cells coexpress 5-HT1AR and 5-HT2AR (Amargós-Bosch et al., 2004; Andrade, 2011). When we infused a 5-HT1AR agonist (8-OH DPAT) into the mPFC before the retention test, we found a deficit in the level of discrimination between the congruent and incongruent object, similar to the one described for the 5-HT2AR antagonist in the OIC task (ANOVA, $F_{(4)}=6.685, p<0.05$; Fig. 5B). Activating 5-HT1AR also affected the total exploratory time, something that we did not see for any of the other drugs used. These results indicate that serotonin signaling in $\mathrm{mPFC}$ controls retrieval through both the 5-HT2AR and the 5-HT1AR. 
A

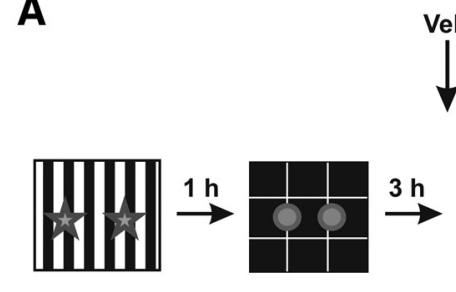

Sample 1

Sample 2

C

D

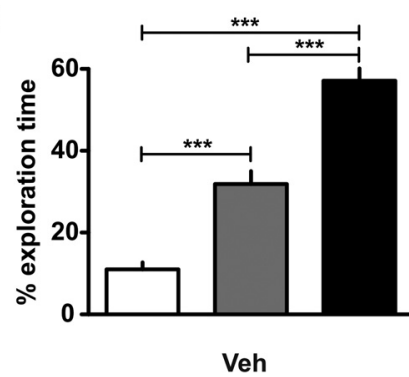

B

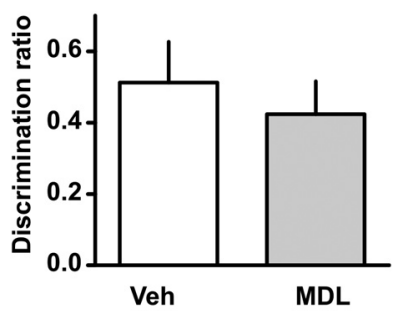

pus (Veh/Musc), (3) rats injected with MDL 11,939 in $\mathrm{mPFC}$ on one hemisphere and muscimol in the hippocampus in the contralateral one (MDL/Musc contra), and (4) rats injected with MDL 11,939 in mPFC in one hemisphere and muscimol in the hippocampus of the same hemisphere (MDL/ Musc ipsi). An ANOVA analysis showed there were significant differences between the groups $\left(F_{(4)}=5.529, p<0.005\right)$. We first confirmed our previous experiment showing that rats infused bilaterally with MDL 11,939 in the mPFC and vehicle in the hippocampus (MDL/Veh group) showed a deficit in the OIC task as described previously (Fig. 6C). Then, the effect of bilateral inactivation of the hippocampus was tested in the Veh/Musc group. Bilateral infusion of muscimol into the hippocampus produced a profound deficit in the OIC task $(p<$ 0.05 ), similar to the one observed by blockade of the 5-HT2AR in the cortex (Fig. 6C). The bilateral inactivation groups showed that both the 5-HT2AR in the $\mathrm{mPFC}$ and activity in the hippocampus are necessary for the correct resolution during the OIC task. To further investigate whether the interaction between the two structures is also necessary in the OIC task, we tested the $\mathrm{MDL} / \mathrm{Musc}$ contralateral group. We found a deficit similar to the one observed for the bilateral inactivation of the hippocampus or bilateral infusion of MDL into the MPFC (Fig. $6 C ; p<0.05$, for multiple comparisons). Other disconnection studies suggest that, as described for the hippocampus and perirhinal cortex, the more dominant interactions between the mPFC and the hippocampus are ipsilateral (Churchwell et al., 2010; Churchwell and Kesner, 2011). To confirm that the main interaction between the $\mathrm{mPFC}$ and hippocampus is ipsilateral, we analyzed the effect of the ipsilateral infusion of MDL 11,939 in the mPFC and muscimol into the hippocampus (MDL/Musc ipsi group). This procedure should allow normal interactions between the MPFC and hippocampus in one hemisphere. We found normal levels of discrimination in the OIC in this group (Fig. $6 C ; p>0.05$, multiple comparisons). These results suggest that the interaction between $\mathrm{mPFC}$ and the hippocampus is required during retrieval in the OIC task.

\section{Connectivity between the MPFC and hippocampus is required for the OIC task}

We next wanted to analyze whether mPFC was involved in the retrieval of hippocampal memory traces. For this experiment, rats were implanted with dwelling cannulae in both the $\mathrm{MPFC}$ and the dorsal hippocampus. We had four different groups that were simultaneously tested: (1) rats injected bilaterally with MDL 11,939 in the $\mathrm{mPFC}$ and vehicle in the hippocampus (MDL/Veh), (2) rats injected bilaterally with vehicle in the MPFC and muscimol in the hippocam-

\section{Discussion}

This study examined the role of mPFC 5-HT2R during retrieval of different versions of the novel object preference task that involve different types of to-be-remembered information. Our main findings are that (1) 5HT2AR in $\mathrm{mPFC}$ is required for retrieval of object recognition memory only in the cases in which the task cannot be solved by a single item strategy and (2) connectivity between $\mathrm{mPFC}$ and the hippocampus is necessary for 
retrieval of an OIC memory. The SOR can be solved by using an item-only strategy, but TMOR and OIC tasks require that the animal remembers an association of the objects and their relative position in time or to the objects and the context in which they have seen them. Retrieval of both TMOR and OIC memories, but not SOR memory, requires 5-HT2AR function in mPFC. This might indicate that there is something qualitatively different between these behavioral paradigms in terms of $\mathrm{mPFC}$ requirement during retrieval.

Other studies have previously dissociated $\mathrm{mPFC}$ requirements in object preference tasks. For example, Barker et al. (2007) found that mPFC excitotoxic lesions affected performance in TMOR and in an object-in-place task in which the animals have to remember which object has been seen and where it was. MPFC lesions did not have any effect in an SOR or in an object-location task in which one of the two objects seen during the study phase is displaced to a novel location during test. However, ours is the first study, to our knowledge, to establish a role for $\mathrm{MPFC}$ serotonin receptors in the process of remembering this type of information. Moreover, our results establish that serotoninergic signaling in $\mathrm{mPFC}$ is coupled to hippocampal activity during retrieval of the OIC task.

Our results are consistent with other animal studies like the ones mentioned, and also with human findings indicating that damage to dorsolateral PFC moderately affects standard item recognition (Wheeler and Stuss, 2003), but profoundly affects performance in tasks that require a recollection type of strategy (Janowsky et al., 1989; Gershberg and Shimamura, 1995; Alexander et al., 2003).

What is the mechanism by which $\mathrm{mPFC}$ participates in TMOR and OIC performance during retrieval? One possibility is that after blockade of 5-HT2AR in mPFC, rats are not able to appropriately select between competing memory traces, like during extinction (Quirk et al., 2006). During the test session of the OIC task, both objects are familiar, so the rat must be able to retrieve the object-context association rather than the item-only memory trace to select the relevant behavior. Thus, blockade of 5-HT2AR in mPFC might result in failure to identify a specific combination of an object and a context. It is unlikely that rats injected with the 5-HT2AR antagonist are impaired at remembering the context, since this treatment does not affect retrieval in an object-location task (Barker et al., 2007). In this sense, Navawongse and Eichenbaum (2013) have shown that mPFC inactivation in the rat decreases selectivity of hippocampal place cells for particular object-location combinations in a context-guided object association task. This is consistent with the view that mPFC does not participate in the spatial representation, but biases retrieval and selection of the appropriate contextual memory. Another possibility might be that the animals do identify the correct memory

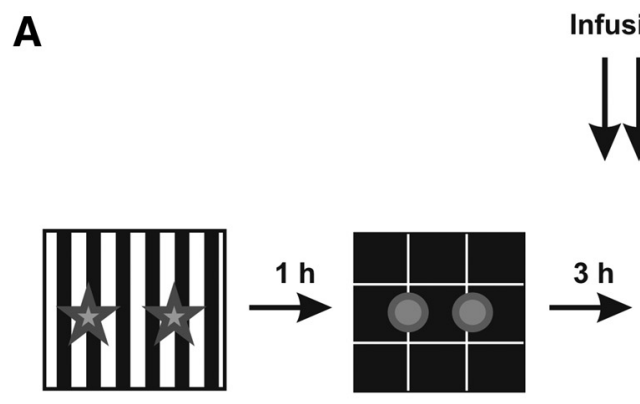

Infusions

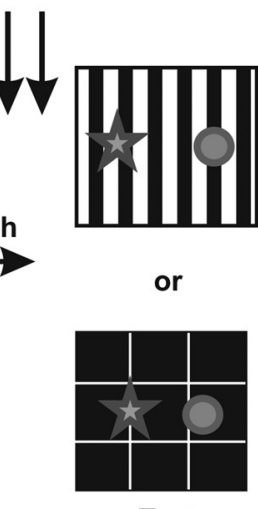

Sample 2

Test

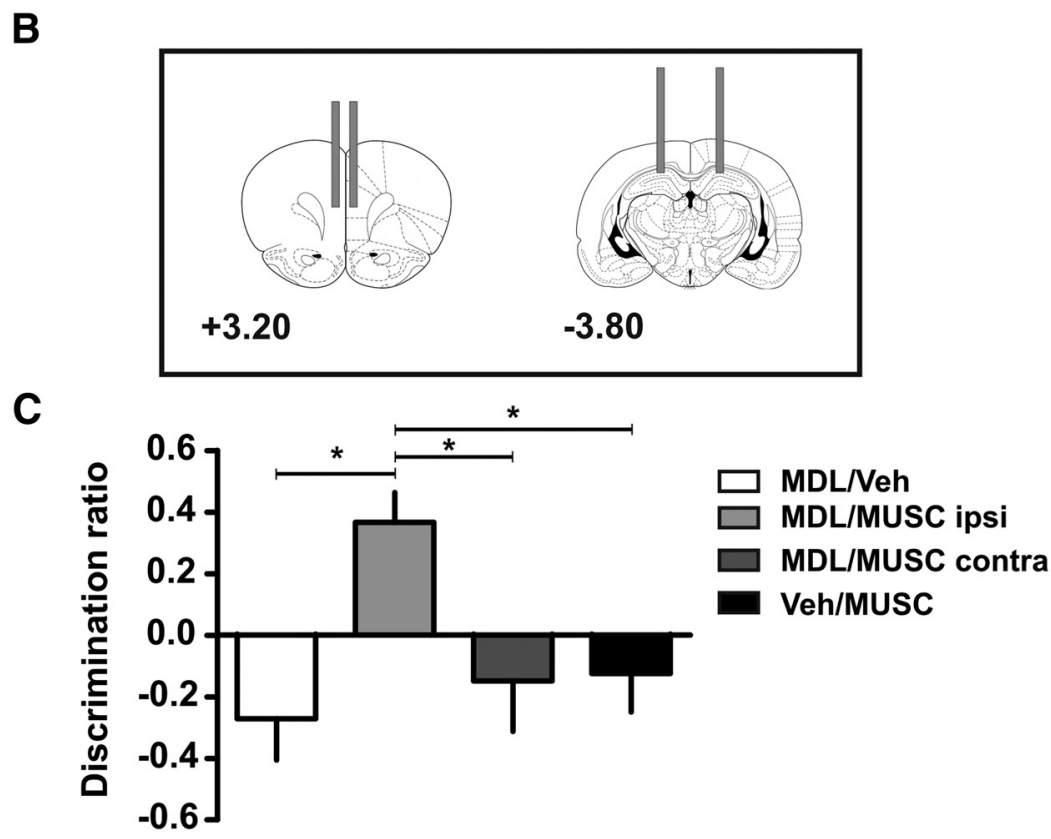

Figure 6. Blockade of 5-HT2AR in mPFC and activity in the hippocampus contralaterally affects the retrieval in the OIC task. A, Training and testing scheme. $\boldsymbol{B}$, Illustration of the locations of the injection cannula tips in the mPFC and hippocampus. The numbers show distances from bregma. C, Effects of either contralateral (MDL/MUSC contra) or ipsilateral (MDL/MUSC ipsi) disconeen the MPFC and hippocampus on performance during the OIC task. MDL 11,939 or vehicle (Veh) was infused in PFC while muscimol (MUSC) or Veh was infused into the dorsal hippocampus. Deficits in the ability to discriminate between and Veh/MUSC) but not in the MDL/MUSC ipsi condition. MDL 11,939 and muscimol were infused 15 min before the test session; $n=5-9$ per group, ${ }^{*} p<0.05$ ANOVA followed by Tukey's multiple comparisons.

traces, but are unable to select the appropriate motor response. Our experiments do not allow distinguishing between these two alternatives.

An interesting explanation could be that the animals fail at source monitoring, the ability to identify the source of remembered information (Johnson et al., 1993), for example, identifying when or where certain information was acquired. This process is suggested to be an essential part of episodic memory retrieval. Failure in source monitoring might be accompanied by misidentification of items or false memories (Johnson et al., 1993; Farovik et al., 2008). The experiment depicted in Figure 5 indicates that normal animals show an increasing degree of preference for congruent, incongruent, and novel objects. However, infusion of MDL 11,939 in mPFC equalizes exploration levels for congruent and incongruent objects, sparing novel object preference. Our results suggest that the animals do remember having 
seen the objects, they just do not remember in which context they have seen them. Alternatively, the animals might falsely recall having seen the incongruent object in the testing context. Absolute levels of exploration suggest that the results could be a mixture of both impairments.

In agreement with our results, older human adults carrying a short allele of the serotonin transporter show an impairment in a source memory recognition task associated with less neural activity in PFC, compared with control carrying the long allele $(\mathrm{Pa}-$ checo et al., 2012). This suggests that 5-HT signaling in PFC, possibly through activation of 5-HT2AR, is important for episodic memory in humans.

The PFC is highly enriched in 5-HT1AR and 5-HT2AR. In particular, 5-HT2AR is the main excitatory receptor type in the PFC. There is clear evidence that activation of 5-HT2AR modulates the response of PFC cells (Andrade, 2011). Interestingly, 5-HT1AR (a $\mathrm{G}_{\mathrm{i}}$-coupled receptor) and 5-HT2AR appear to be coexpressed in a large fraction of pyramidal cortical cells. This suggests that 5-HT1A and 5-HT2A receptors may cooperate to regulate how pyramidal neurons encode excitatory inputs (Araneda and Andrade, 1991; Béique et al., 2004). Interestingly, our results indicate that 5-HT1A and 5-HT2A receptors in $\mathrm{mPFC}$ might have opposite functions during retrieval of the OIC memory. This suggests that serotonin might exert a fine regulation over memory retrieval. Slice electrophysiological experiments indicate that one possible mechanism by which they could be doing this is by modulating the gain of mPFC neurons. In addition, in vivo blockade of 5-HT2AR in the mPFC affects gamma oscillations, suggesting that 5 -HT2AR regulates the function of this structure at a system level (Puig and Gulledge, 2011). Although our experiments do not address how blocking 5-HT2AR might be affecting interference resolution, we could hypothesize that blocking 5-HT2AR during retrieval might alter the gain modulation of the cells and also the gamma oscillation activity of the system, altering the output to target structures such as the hippocampus.

It has recently been shown that the $\mathrm{mPFC}$ is connected with the hippocampus indirectly through the nucleus reuniens of the thalamus (Xu and Südhof, 2013). These authors very elegantly show that blocking the $\mathrm{mPFC}$ projections to the nucleus reuniens affects the activity of the hippocampus and increases the levels of generalization of a fear memory, suggesting that the three structures form a circuit involved in memory generalization. Our own experiments suggest that there is a functional connection between the mPFC and the hippocampus that is important for the correct performance in the OIC task. Then, we can hypothesize that blocking 5-HT2AR in the mPFC might result in changes to the nucleus reuniens and consequently its connection with the hippocampus. In summary, we have shown that serotonin signaling through the 5-HT2AR is required for the correct capability of the $\mathrm{mPFC}$ to guide retrieval of the more relevant memory trace. Retrieval of an episodic memory can be triggered by particular cues belonging to the original memory but that are usually common to other memory traces. We believe that the role of the mPFC could be to suppress memory interference allowing the selection of the correct memory trace during retrieval. Our results point at serotonin as a modulator of this process by means of the activation of 5-HT2AR. This mechanism could be seen as part of a broader set of cognitive functions. Accumulating evidence suggests that 5-HT2ARs are involved in behavioral flexibility. Interestingly, a recent paper has shown that systemic injection of 5-HT2AR antagonist enhances strategy switching by inhibiting responses on a previously relevant strategy (Baker et al., 2011).
One can argue that this process might require the inhibition of memory traces related to the previous strategy used to allow a change in the behavioral response. In this way, blockade of 5-HT2AR might impair retrieval of the previous strategy making it easier to learn the new one. Behavioral flexibility, as a part of cognitive flexibility processes is affected in different psychiatric conditions such as obsessive compulsive disorder (El Mansari and Blier, 2006), autism spectrum disorders (Brune et al., 2006), and schizophrenia (Clarke et al., 2004; Uçok et al., 2007). Selection of the relevant memory traces and the control of retrieval might be crucial for behavioral flexibility. In this scenario, specific pharmacological manipulations of the 5-HT2AR could ameliorate cognitive deficits associated with these disorders.

\section{References}

Aggleton JP, Blindt HS, Rawlins JN (1989) Effects of amygdaloid and amygdaloid-hippocampal lesions on object recognition and spatial working memory in rats. Behav Neurosci 103:962-974. CrossRef Medline

Alexander MP, Stuss DT, Fansabedian N (2003) California Verbal Learning Test: performance by patients with focal frontal and non-frontal lesions. Brain 126:1493-1503. CrossRef Medline

Amargós-Bosch M, Bortolozzi A, Puig MV, Serrats J, Adell A, Celada P, Toth M, Mengod G, Artigas F (2004) Co-expression and in vivo interaction of serotonin $1 \mathrm{~A}$ and serotonin2A receptors in pyramidal neurons of prefrontal cortex. Cereb Cortex 14:281-299. CrossRef Medline

Anderson MC, Ochsner KN, Kuhl B, Cooper J, Robertson E, Gabrieli SW, Glover GH, Gabrieli JD (2004) Neural systems underlying the suppression of unwanted memories. Science 303:232-235. CrossRef Medline

Andrade R (2011) Serotonergic regulation of neuronal excitability in the prefrontal cortex. Neuropharmacology 61:382-386. CrossRef Medline

Araneda R, Andrade R (1991) 5-Hydroxytryptamine2 and 5-hydroxytryptamine $1 \mathrm{~A}$ receptors mediate opposing responses on membrane excitability in rat association cortex. Neuroscience 40:399-412. CrossRef Medline

Baker PM, Thompson JL, Sweeney JA, Ragozzino ME (2011) Differential effects of 5-HT(2A) and 5-HT(2C) receptor blockade on strategyswitching. Behav Brain Res 219:123-131. CrossRef Medline

Barker GR, Warburton EC (2011) When is the hippocampus involved in recognition memory? J Neurosci 31:10721-10731. CrossRef Medline

Barker GR, Bird F, Alexander V, Warburton EC (2007) Recognition memory for objects, place, and temporal order: a disconnection analysis of the role of the medial prefrontal cortex and perirhinal cortex. J Neurosci 27:2948-2957. CrossRef Medline

Bartko SJ, Winters BD, Cowell RA, Saksida LM, Bussey TJ (2007) Perirhinal cortex resolves feature ambiguity in configural object recognition and perceptual oddity tasks. Learn Mem 14:821-832. CrossRef Medline

Béíque JC, Campbell B, Perring P, Hamblin MW, Walker P, Mladenovic L, Andrade R (2004) Serotonergic regulation of membrane potential in developing rat prefrontal cortex: coordinated expression of 5-hydroxytryptamine (5-HT)1A, 5-HT2A, and 5-HT7 receptors. J Neurosci 24:4807-4817. CrossRef Medline

Boulougouris V, Dalley JW, Robbins TW (2007) Effects of orbitofrontal, infralimbic and prelimbic cortical lesions on serial spatial reversal learning in the rat. Behavioural brain research 179:219-228. CrossRef Medline

Brown MW, Aggleton JP (2001) Recognition memory: what are the roles of the perirhinal cortex and hippocampus? Nat Rev Neurosci 2:51-61. CrossRef Medline

Brown MW, Wilson FA, Riches IP (1987) Neuronal evidence that inferomedial temporal cortex is more important than hippocampus in certain processes underlying recognition memory. Brain Res 409:158-162. CrossRef Medline

Browning PG, Easton A, Buckley MJ, Gaffan D (2005) The role of prefrontal cortex in object-in-place learning in monkeys. Eur J Neurosci 22:32813291. CrossRef Medline

Brune CW, Kim SJ, Salt J, Leventhal BL, Lord C, Cook EH Jr (2006) 5-HTTLPR Genotype-specific phenotype in children and adolescents with autism. Am J Psychiatry 163:2148-2156. CrossRef Medline

Burgess N, Maguire EA, Spiers HJ, O'Keefe J (2001) A temporoparietal and prefrontal network for retrieving the spatial context of lifelike events. Neuroimage 14:439-453. CrossRef Medline

Bussey TJ, Duck J, Muir JL, Aggleton JP (2000) Distinct patterns of behav- 
ioural impairments resulting from fornix transection or neurotoxic lesions of the perirhinal and postrhinal cortices in the rat. Behav Brian Res 111:187-202. CrossRef Medline

Carli M, Baviera M, Invernizzi RW, Balducci C (2006) Dissociable contribution of 5-HT1A and 5-HT2A receptors in the medial prefrontal cortex to different aspects of executive control such as impulsivity and compulsive perseveration in rats. Neuropsychopharmacology 31:757-767. CrossRef Medline

Churchwell JC, Kesner RP (2011) Hippocampal-prefrontal dynamics in spatial working memory: interactions and independent parallel processing. Behav Brain Res 225:389-395. CrossRef Medline

Churchwell JC, Morris AM, Musso ND, Kesner RP (2010) Prefrontal and hippocampal contributions to encoding and retrieval of spatial memory. Neurobiol Learn Mem 93:415-421. CrossRef Medline

Clarke HF, Dalley JW, Crofts HS, Robbins TW, Roberts AC (2004) Cognitive inflexibility after prefrontal serotonin depletion. Science 304:878880. CrossRef Medline

de Quervain DJ, Henke K, Aerni A, Coluccia D, Wollmer MA, Hock C, Nitsch RM, Papassotiropoulos A (2003) A functional genetic variation of the 5-HT2a receptor affects human memory. Nat Neurosci 6:1141-1142. CrossRef Medline

Eacott MJ, Norman G (2004) Integrated memory for object, place, and context in rats: a possible model of episodic-like memory? J Neurosci 24: 1948-1953. CrossRef Medline

Easton A, Webster LA, Eacott MJ (2012) The episodic nature of episodiclike memories. Learn Mem 19:146-150. CrossRef Medline

El Mansari M, Blier P (2006) Mechanisms of action of current and potential pharmacotherapies of obsessive-compulsive disorder. Prog Neuropsychopharmacol Biol Psychiatry 30:362-373. CrossRef Medline

Ennaceur A, Aggleton JP (1994) Spontaneous recognition of object configurations in rats: effects of fornix lesions. Exp Brain Res 100:85-92. Medline

Ennaceur A, Neave N, Aggleton JP (1996) Neurotoxic lesions of the perirhinal cortex do not mimic the behavioural effects of fornix transection in the rat. Behav Brain Res 80:9-25. CrossRef Medline

Ergorul C, Eichenbaum H (2004) The hippocampus and memory for "what," "where," and "when." Learn Mem 11:397-405.

Fahy FL, Riches IP, Brown MW (1993) Neuronal activity related to visual recognition memory: long-term memory and the encoding of recency and familiarity information in the primate anterior and medial inferior temporal and rhinal cortex. Exp Brain Res 96:457-472. Medline

Farovik A, Dupont LM, Arce M, Eichenbaum H (2008) Medial prefrontal cortex supports recollection, but not familiarity, in the rat. J Neurosci 28:13428-13434. CrossRef Medline

Ferbinteanu J, Kennedy PJ, Shapiro ML (2006) Episodic memory-from brain to mind. Hippocampus 16:691-703. CrossRef Medline

Forwood SE, Bartko SJ, Saksida LM, Bussey TJ (2007) Rats spontaneously discriminate purely visual, two-dimensional stimuli in tests of recognition memory and perceptual oddity. Behav Neurosci 121:1032-1042. CrossRef Medline

Frankland PW, Bontempi B (2005) The organization of recent and remote memories. Nat Rev Neurosci 6:119-130. CrossRef Medline

Fuster JM (2001) The prefrontal cortex-an update: time is of the essence. Neuron 30:319-333. CrossRef Medline

Gaffan D (1992) Amnesia for complex naturalistic scenes and for objects following fornix transection in the Rhesus monkey. Eur J Neurosci 4:381388. CrossRef Medline

Gershberg FB, Shimamura AP (1995) Impaired use of organizational strategies in free recall following frontal lobe damage. Neuropsychologia 33: 1305-1333. CrossRef Medline

Goldman-Rakic PS, Selemon LD, Schwartz ML (1984) Dual pathways connecting the dorsolateral prefrontal cortex with the hippocampal formation and parahippocampal cortex in the rhesus monkey. Neuroscience 12:719-743. CrossRef Medline

Hannesson DK, Howland JG, Phillips AG (2004a) Interaction between perirhinal and medial prefrontal cortex is required for temporal order but not recognition memory for objects in rats. J Neurosci 24:4596-4604. CrossRef Medline

Hannesson DK, Vacca G, Howland JG, Phillips AG (2004b) Medial prefrontal cortex is involved in spatial temporal order memory but not spatial recognition memory in tests relying on spontaneous exploration in rats. Behav Brain Res 153:273-285. CrossRef Medline

Hayes SM, Ryan L, Schnyer DM, Nadel L (2004) An fMRI study of episodic memory: retrieval of object, spatial, and temporal information. Behav Neurosci 118:885-896. CrossRef Medline

Janowsky JS, Shimamura AP, Squire LR (1989) Source memory impairment in patients with frontal lobe lesions. Neuropsychologia 27:1043-1056. CrossRef Medline

Johnson MK, Hashtroudi S, Lindsay DS (1993) Source monitoring. Psychol Bull 114:3-28. CrossRef Medline

Kennett GA, Wood MD, Bright F, Trail B, Riley G, Holland V, Avenell KY, Stean T, Upton N, Bromidge S, Forbes IT, Brown AM, Middlemiss DN, Blackburn TP (1997) SB 242084, a selective and brain penetrant 5-HT2C receptor antagonist. Neuropharmacology 36:609-620. CrossRef Medline

Kesner RP, Ragozzino ME (2003) The role of the prefrontal cortex in objectplace learning: a test of the attribute specificity model. Behav Brain Res 146:159-165. CrossRef Medline

Langston RF, Wood ER (2010) Associative recognition and the hippocampus: differential effects of hippocampal lesions on object-place, objectcontext and object-place-context memory. Hippocampus 20:1139-1153. Medline

Li L, Miller EK, Desimone R (1993) The representation of stimulus familiarity in anterior inferior temporal cortex. J Neurophysiol 69:1918-1929. Medline

Martín-Ruiz R, Puig MV, Celada P, Shapiro DA, Roth BL, Mengod G, Artigas F (2001) Control of serotonergic function in medial prefrontal cortex by serotonin-2A receptors through a glutamate-dependent mechanism. J Neurosci 21:9856-9866. Medline

Meneses A (2007) Stimulation of 5-HT1A, 5-HT1B, 5-HT2A/2C, 5-HT3 and 5-HT4 receptors or 5-HT uptake inhibition: short- and long-term memory. Behav Brain Res 184:81-90. CrossRef Medline

Meneses A, Terrón JA, Hong E (1997) Effects of the 5-HT receptor antagonists GR127935 (5-HT1B/1D) and MDL100907 (5-HT2A) in the consolidation of learning. Behav Brain Res 89:217-223. CrossRef Medline

Meunier M, Bachevalier J, Mishkin M, Murray EA (1993) Effects on visual recognition of combined and separate ablations of the entorhinal and perirhinal cortex in rhesus monkeys. J Neurosci 13:5418-5432. Medline

Miller EK (2000) The prefrontal cortex and cognitive control. Nat Rev Neurosci 1:59-65. CrossRef Medline

Miller EK, Cohen JD (2001) An integrative theory of prefrontal cortex function. Annu Rev Neurosci 24:167-202. CrossRef Medline

Miller P, Wang XJ (2006) Inhibitory control by an integral feedback signal in prefrontal cortex: a model of discrimination between sequential stimuli. Proc Natl Acad Sci U S A 103:201-206. CrossRef Medline

Murray EA, Bussey TJ (1999) Perceptual-mnemonic functions of the perirhinal cortex. Trends Cogn Sci 3:142-151. CrossRef Medline

Navawongse R, Eichenbaum H (2013) Distinct pathways for rule-based retrieval and spatial mapping of memory representations in hippocampal neurons. J Neurosci 33:1002-1013. CrossRef Medline

Nyberg L, Persson J, Habib R, Tulving E, McIntosh AR, Cabeza R, Houle S (2000) Large scale neurocognitive networks underlying episodic memory. J Cogn Neurosci 12:163-173. CrossRef Medline

Pacheco J, Beevers CG, McGeary JE, Schnyer DM (2012) Memory monitoring performance and PFC activity are associated with 5-HTTLPR genotype in older adults. Neuropsychologia 50:2257-2270. CrossRef Medline

Pehek EA, Nocjar C, Roth BL, Byrd TA, Mabrouk OS (2006) Evidence for the preferential involvement of 5-HT2A serotonin receptors in stress- and drug-induced dopamine release in the rat medial prefrontal cortex. Neuropsychopharmacology 31:265-277. CrossRef Medline

Petrovich GD, Canteras NS, Swanson LW (2001) Combinatorial amygdalar inputs to hippocampal domains and hypothalamic behavior systems. Brain Res Brain Res Rev 38:247-289. CrossRef Medline

Price JL (1999) Prefrontal cortical networks related to visceral function and mood. Ann N Y Acad Sci 877:383-396. CrossRef Medline

Puig MV, Gulledge AT (2011) Serotonin and prefrontal cortex function: neurons, networks, and circuits. Mol Neurobiol 44:449-464. CrossRef Medline

Puig MV, Celada P, Artigas F (2004) [Serotonergic control of prefrontal cortex]. Rev Neurol 39:539-547. Medline

Puig MV, Artigas F, Celada P (2005) Modulation of the activity of pyramidal neurons in rat prefrontal cortex by raphe stimulation in vivo: involvement of serotonin and GABA. Cereb Cortex 15:1-14. Medline

Quirk GJ, Garcia R, González-Lima F (2006) Prefrontal mechanisms in ex- 
tinction of conditioned fear. Biol Psychiatry 60:337-343. CrossRef Medline

Robbins TW (1996) Dissociating executive functions of the prefrontal cortex. Philos Trans R Soc Lond B Biol Sci 351:1463-1470; discussion 14701471. Medline

Squire LR (2004) Memory systems of the brain: a brief history and current perspective. Neurobiol Learn Mem 82:171-177. CrossRef Medline

Uçok A, Alpsan H, Cakir S, Saruhan-Direskeneli G (2007) Association of a serotonin receptor $2 \mathrm{~A}$ gene polymorphism with cognitive functions in patients with schizophrenia. Am J Med Genet B Neuropsychiatr Genet 144B:704-707. CrossRef Medline

Wagner M, Schuhmacher A, Schwab S, Zobel A, Maier W (2008) The His452Tyr variant of the gene encoding the 5-HT2A receptor is specifically associated with consolidation of episodic memory in humans. Int J Neuropsychopharmacol 11:1163-1167. CrossRef Medline

Warburton EC, Brown MW (2010) Findings from animals concerning when interactions between perirhinal cortex, hippocampus and medial prefrontal cortex are necessary for recognition memory. Neuropsychologia 48:2262-2272. CrossRef Medline

Wheeler MA, Stuss DT (2003) Remembering and knowing in patients with frontal lobe injuries. Cortex 39:827-846. CrossRef Medline
Wheeler MA, Stuss DT, Tulving E (1995) Frontal lobe damage produces episodic memory impairment. J Int Neuropsychol Soc 1:525-536. CrossRef Medline

Wilson DI, Langston RF, Schlesiger MI, Wagner M, Watanabe S, Ainge JA (2013) Lateral entorhinal cortex is critical for novel object-context recognition. Hippocampus 23:352-366. CrossRef Medline

Winstanley CA, Chudasama Y, Dalley JW, Theobald DE, Glennon JC, Robbins TW (2003) Intra-prefrontal 8-OH-DPAT and M100907 improve visuospatial attention and decrease impulsivity on the five-choice serial reaction time task in rats. Psychopharmacology 167:304-314. Medline

Winters BD, Forwood SE, Cowell RA, Saksida LM, Bussey TJ (2004) Double dissociation between the effects of peri-postrhinal cortex and hippocampal lesions on tests of object recognition and spatial memory: heterogeneity of function within the temporal lobe. J Neurosci 24:5901-5908. CrossRef Medline

Winters BD, Saksida LM, Bussey TJ (2010) Implications of animal object memory research for human amnesia. Neuropsychologia 48:2251-2261. CrossRef Medline

Xu W, Südhof TC (2013) A neural circuit for memory specificity and generalization. Science 339:1290-1295. CrossRef Medline 